\title{
UM CONTO HAITIANO
}

\section{Mateus Bruxel ${ }^{1}$}

A jornada é uma estratégia bastante utilizada como recurso narrativo. $\mathrm{O}$ personagem se transforma, evolui e nunca acaba do mesmo jeito que começou. Um conto pode ser um relato breve e conciso ou um relato intencionalmente falso e enganoso. Como escreve o teórico André Rouillé, no livro A fotografia: entre documento e arte contemporânea: "o menor enquadramento é ao mesmo tempo inclusão e exclusão, que o mais ordinário ponto de vista é tomada de posição, que o registro mais espontâneo é construção”. Em 2015 viajei ao Acre para produzir uma reportagem sobre o crescente fluxo migratório de haitianos e senegaleses na fronteira de Brasil, Peru e Bolívia. Foram diversos dias de cobertura e contato com muitas histórias e personagens, que culminaram no retorno em uma viagem de ônibus com um grupo de imigrantes de Rio Branco (AC) para São Paulo (SP). Desde então, passei a acompanhar atentamente esses deslocamentos humanos e seus desdobramentos no país. Em 2019, reencontrei um dos personagens que conheci no Acre vivendo em Porto Alegre. No nosso reencontro, após anos sem contato, soube que ele decidiu vir para o sul por ter conhecido a equipe de reportagem. As imagens deste ensaio, produzidas em 2015 entre o Acre e o caminho até São Paulo, atravessando diversos estados, serviram para reavivar memórias, trazer de volta lembranças e são ponto de partida para um filme ${ }^{2}$.

\footnotetext{
${ }^{1}$ Fotojornalista, filmmaker e especialista em Criação e produção de narrativas Multimídia, Brasil.

${ }^{2}$ Ann fè yon fim (Vamos fazer um filme), disponível em: https://www.youtube.com/watch?v=TQbq5IylGt0
} 


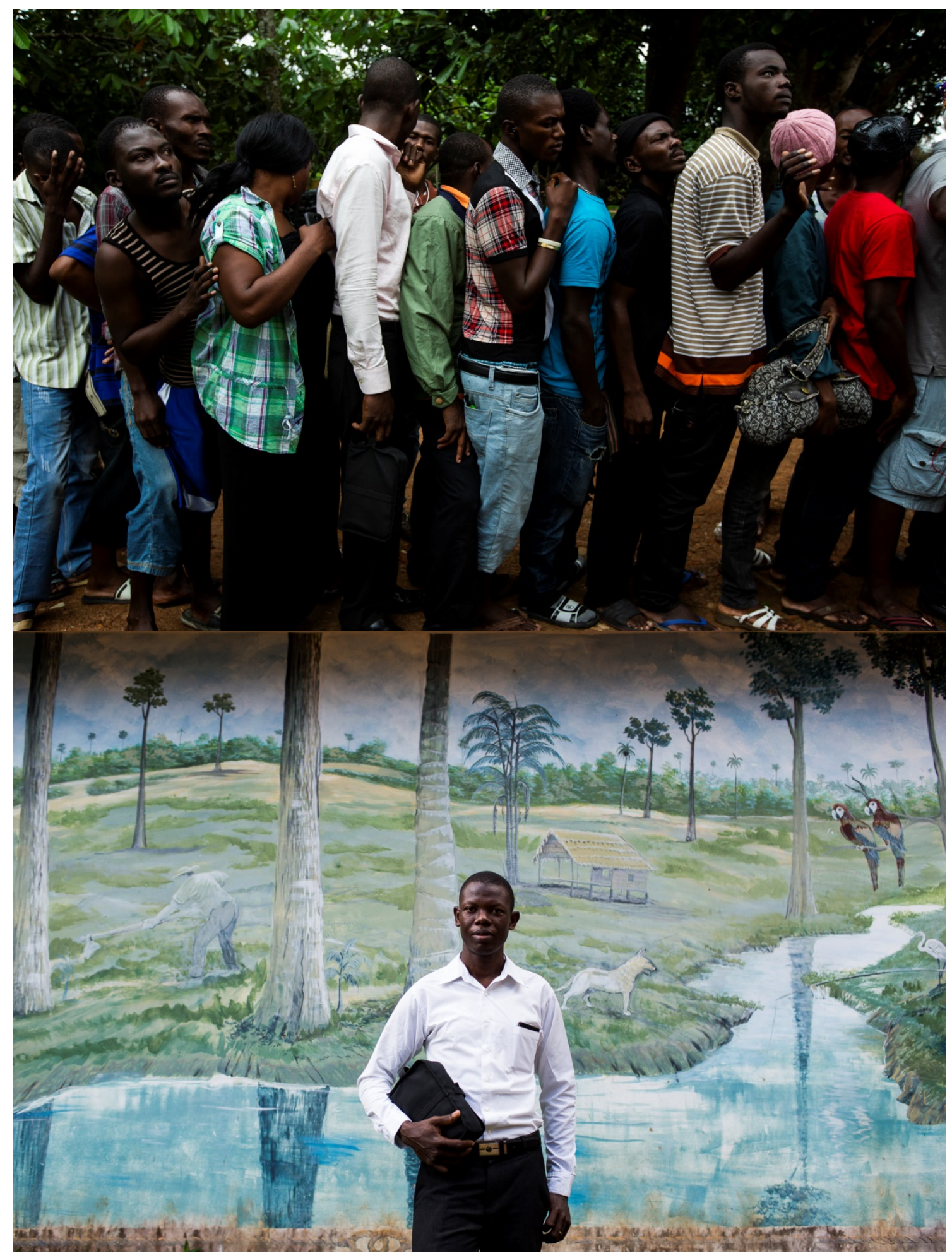




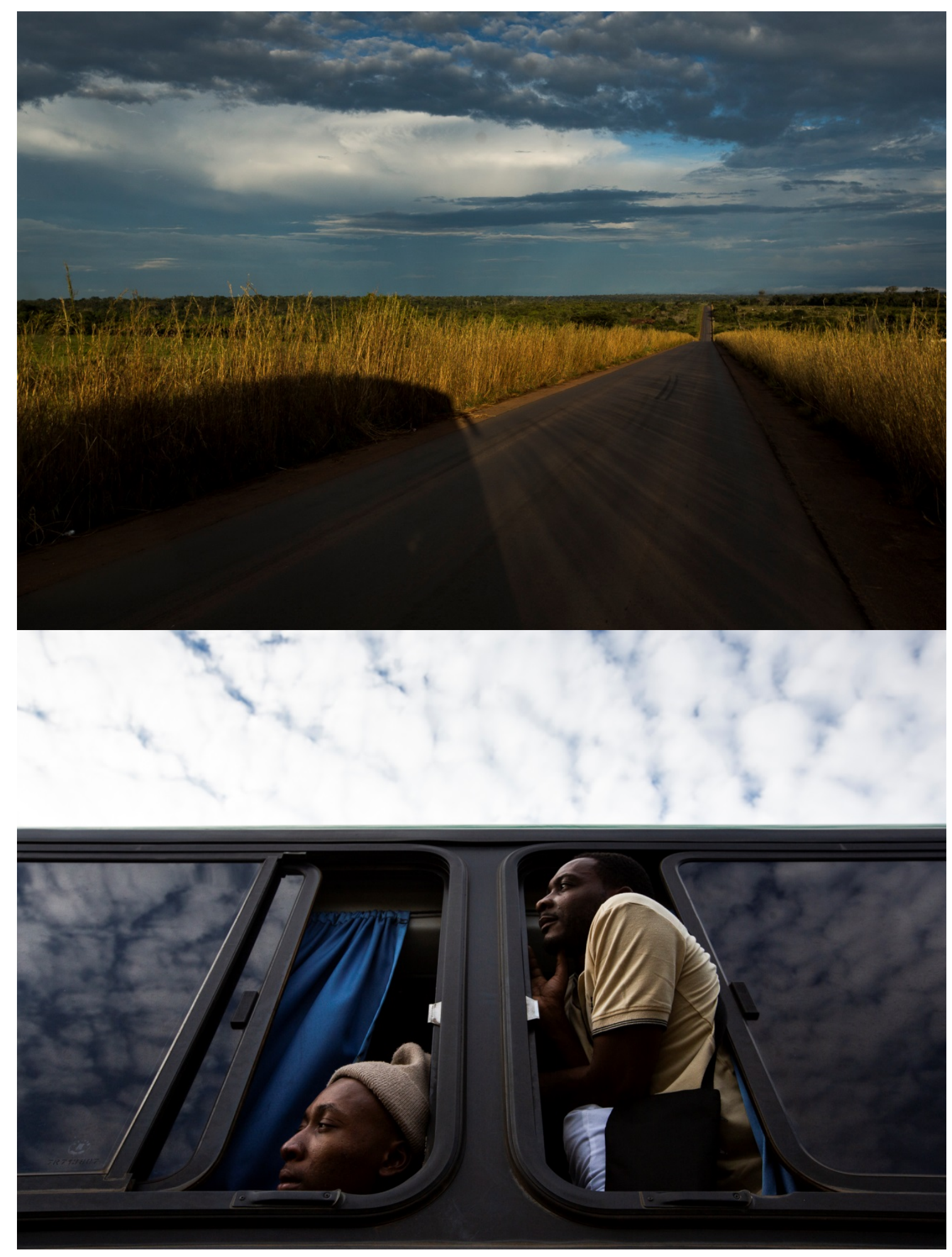




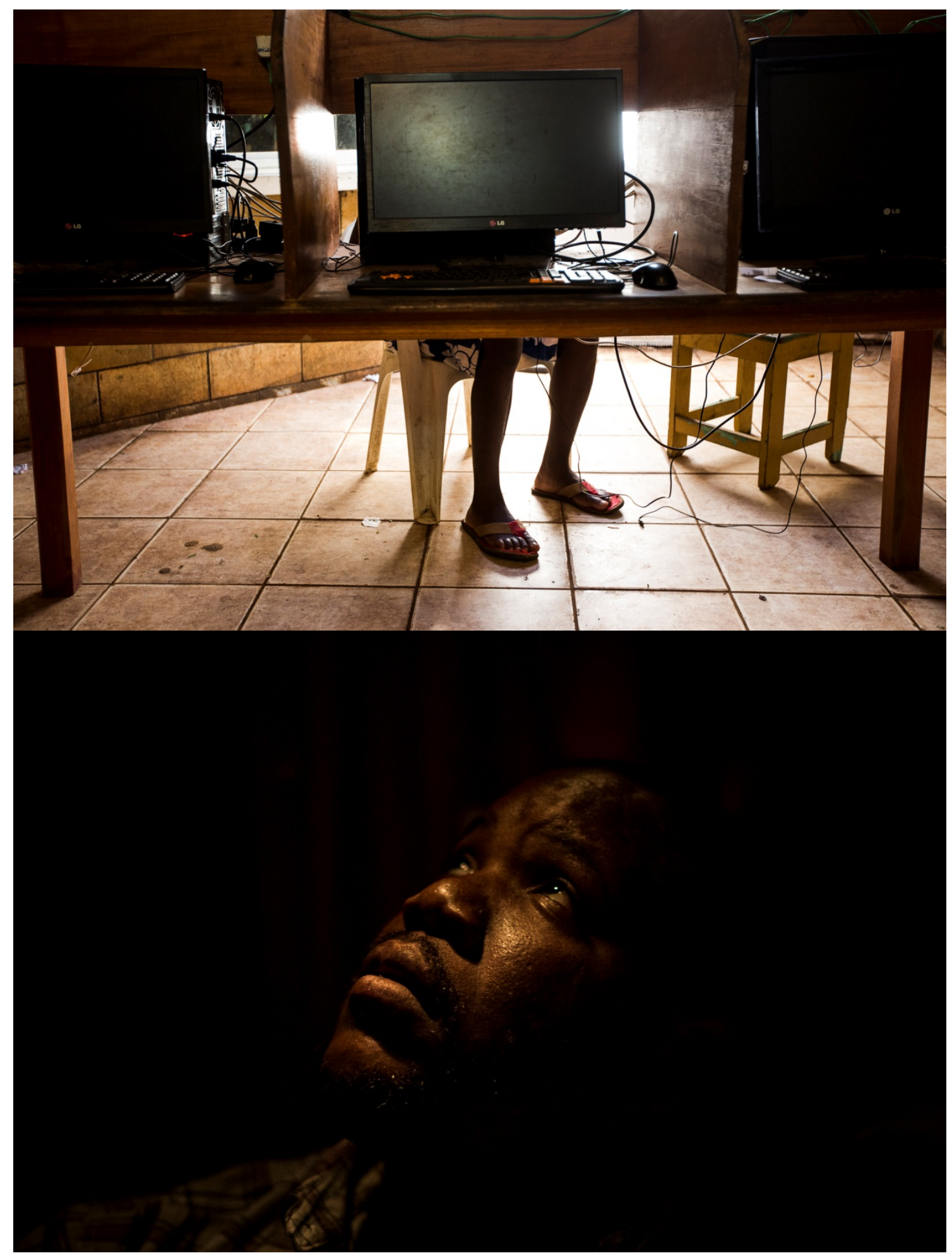




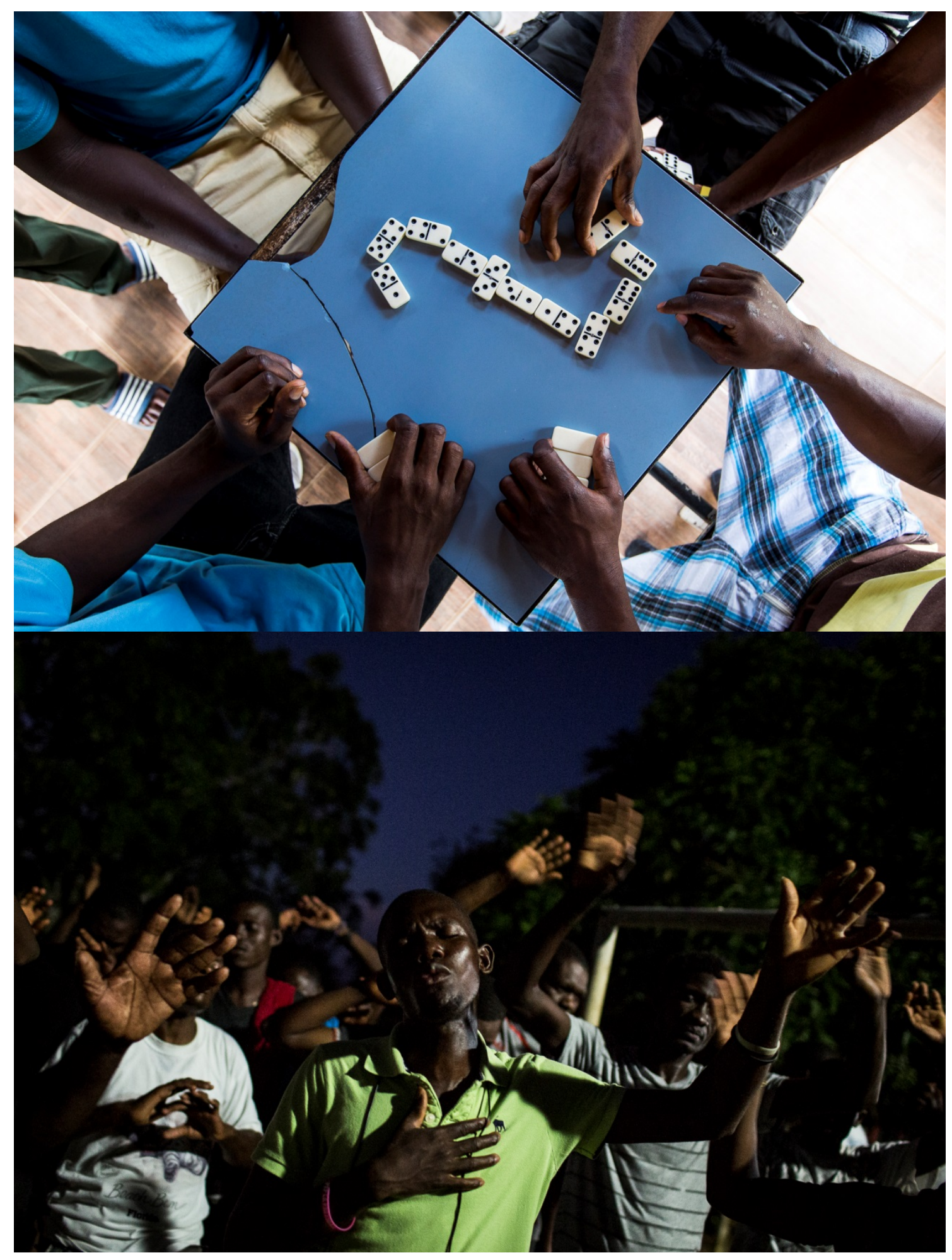




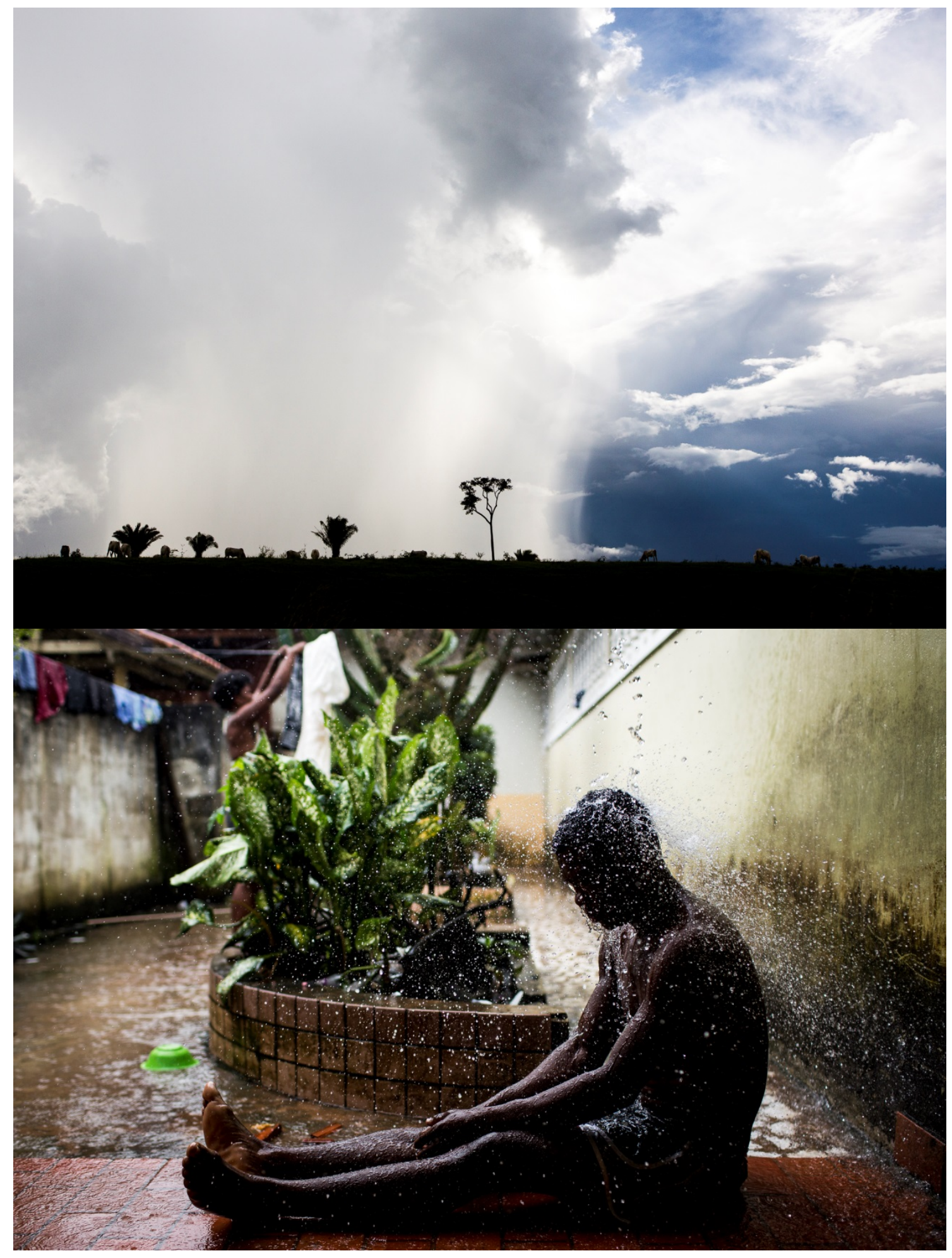

Recebido 01/07/2019

Aprovado 24/07/2019 